\title{
Evidence of transport, sedimentation and coagulation mechanisms in the relaxation of post-volcanic stratospheric aerosols
}

\author{
D. Fussen, F. Vanhellemont, and C. Bingen \\ Institut d'Aéronomie Spatiale de Belgique, Brussels, Belgium \\ Received: 10 May 2001 - Revised: 19 July 2001 - Accepted: 21 August 2001
}

\begin{abstract}
Spatio-temporal distributions of stratospheric aerosols, measured by the ORA instrument from August 1992 until May 1993, are presented in the latitude range $\left(40^{\circ} \mathrm{S}-40^{\circ} \mathrm{N}\right)$. Particle total number density, mode radius and distribution width are derived and interpreted. The respective roles of advection, sedimentation and coagulation are discussed. We also identify clear transport/sedimentation patterns and we show the enhancement of coagulation in stagnation regions. Efficient transport of aerosol particles up to $50 \mathrm{~km}$ is suggested.
\end{abstract}

Key words. Atmospheric composition and structure (aerosols and particles; middle atmosphere-composition and chemistry; volcanic effects)

\section{Introduction}

The stratospheric aerosol layer, mostly known as the Junge layer (Junge et al., 1961), is extremely sensitive to major volcanic eruptions that can inject huge quantities of $\mathrm{SO}_{2}$ into the stratosphere. According to the theory (see for instance Turco et al., 1982), this gas should be a major precursor of aerosol droplets which mainly consist of a mixing of sulfuric acid and liquid water. In particular, the June 1991 eruption of Mount Pinatubo increased the aerosol loading of the stratosphere to about 30 MT (McCormick and Veiga, 1992). During a few years, this exceptional event triggered significant effects on the radiative forcing of the atmosphere (e.g. Labitzke and McCormick, 1992) as well as on the heterogeneous chemical reactions that may change ozone by perturbing the active nitrogen partitioning (e.g. Solomon et al., 1996). Climatological studies of stratospheric aerosol after the Pinatubo eruption (e.g. Thomason et al., 1997) and satellite estimates of stratospheric optical thickness (e.g. Russell et al., 1996) have also been published.

Also, much modelling effort has been devoted to the simulation of Mount Pinatubo aerosols (Zhao et al., 1995; Weisen-

Correspondence to: D. Fussen (didier.fussen@oma.be) stein et al., 1997; Koziol and Pudykiewicz, 1998) and to the understanding of their transport (Rogers et al., 1999). The evolution of the Junge layer has been extensively studied from satellite measurements (Hitchman et al., 1994; Trepte et al., 1994) and the existence of a tropical stratospheric reservoir has been suggested (Grant et al., 1996); the role of the quasi-biennial oscillation in transport to mid-latitudes has been discussed (Choi et al., 1998).

In this work, we present results obtained during the period August 1992-May 1993 from solar occultation data, produced by the Occultation RAdiometer (ORA) instrument developed at the Belgian Institute for Space Aeronomy. While many aerosol climatologies have used integrated quantities like the extinction coefficient or surface area densities, we focussed our attention on the derivation of aerosol particle size distributions and their evolution in space and time during that period.

\section{The ORA instrument and data processing algorithm}

The ORA instrument that was launched onboard the EUropean REtrievable CArrier (EURECA) had the unique opportunity to observe the relaxation of the Mount Pinatubo aerosols with a global coverage of the measurements in the latitude range $\left(40^{\circ} \mathrm{S}-40^{\circ} \mathrm{N}\right)$. The experiment aimed at the atmospheric limb remote sounding of $\mathrm{O}_{3}, \mathrm{NO}_{2}, \mathrm{H}_{2} \mathrm{O}$ and aerosol extinction vertical profiles in the UV to near IR range by using 8 radiometric modules with broadband filters centered of $\lambda=\{259,340,385,435,442,600,943,1013\} \mathrm{nm}$ (see Arijs et al., 1995).

In previous work, we described the vertical and spectral inversion algorithms (Fussen et al., 1997, 1998, 2001a) that allowed us to retrieve the wavelength dependence of the aerosol extinction coefficient. In a recent publication (Fussen et al., 2001b), we developed an optical inversion algorithm capable of deriving aerosol particle size distributions from 

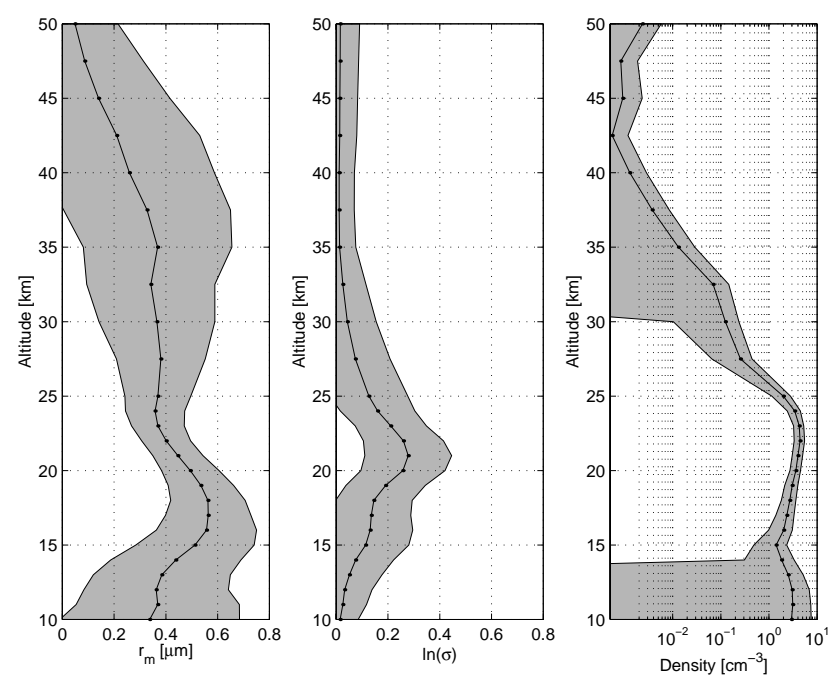

Fig. 1. Mean vertical profiles for $r_{m}, \ln (\sigma)$ and $N$.

the extinction coefficient $\beta(\lambda)$. Briefly, we start from a retrieved quadratic wavelength dependence for $\beta(\lambda)$ like

$\beta(\lambda)=c_{0}+c_{1}\left(\lambda-\lambda_{0}\right)+c_{2}\left(\lambda-\lambda_{0}\right)^{2}$

where $\lambda_{0}=1013 \mathrm{~nm}$ is an arbitrary reference channel. Assuming spherical aerosol droplets of radius $r$ with a generally accepted weight mixing of $75 \%$ of $\mathrm{H}_{2} \mathrm{SO}_{4}$ and $25 \%$ of $\mathrm{H}_{2} \mathrm{O}$ (refractive index $m=1.43$ ), the computed extinction coefficient $\beta_{c}(\lambda)$ may be written as

$\beta_{c}(\lambda)=\int_{0}^{\infty} F(r) Q(r, \lambda) d r$

where $Q(r, \lambda)$ is the extinction cross section computed in the frame of Mie scattering theory. Assuming that the number of retrievable parameters is limited to three, we have expressed the particle size distribution as a lognormal function:

$F(r)=N \frac{1}{r \ln (\sigma) \sqrt{2 \pi}} \exp \left(-\frac{\ln ^{2}\left(r / r_{m}\right)}{2 \ln ^{2}(\sigma)}\right)$

where $N(z), r_{m}(z)$ and $\sigma(z)$ respectively play the role of aerosol particle number density, mode radius and distribution width. The optical inversion aims at determining the set of these parameters that gives the best fit between the computed $\beta_{c}(\lambda)$ and the retrieved $\beta(\lambda)$. Although it is a reasonable assumption, it is important to note the intrinsic limitations of the method. The number of spectral channels of ORA and the other constituents limit the possible number of retrieved parameters but this would also be the case with many more channels in the same spectral range. Indeed, the detection of particles, smaller or larger than the extreme wavelengths of the measurement, is difficult because they produce a vanishing spectral signature that falls below the measurement error level. Therefore, the retrieved distribution should be considered as an effective distribution that reproduces the observed extinction coefficient. The same caveat applies on the analytical form of the particle size distribution. This nonlinear

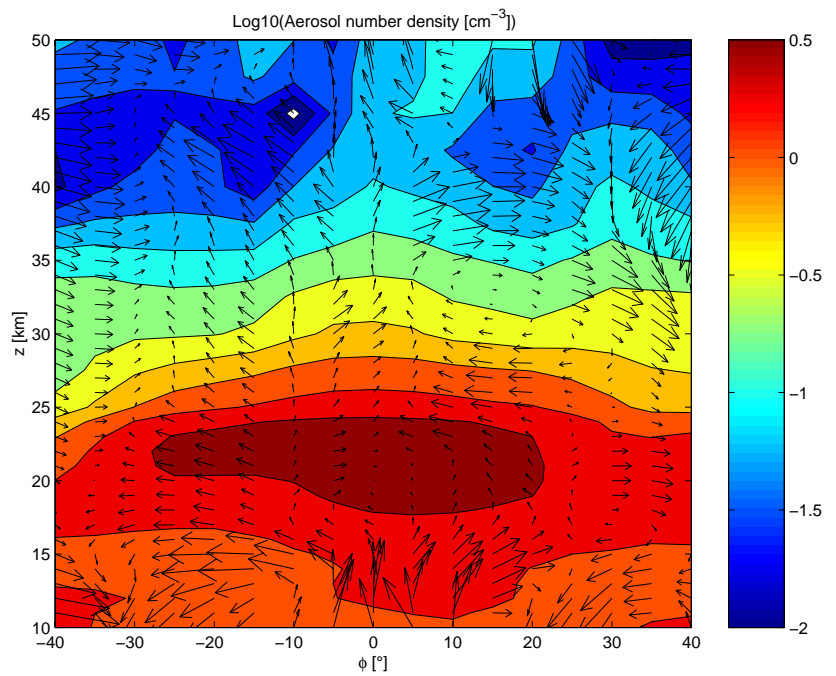

Fig. 2. Contour plot of the decimal logarithm of the time-averaged aerosol total number density. UKMO velocity fields have been superposed.

problem is rather ill-conditioned (Echle et al., 1998) and we were led to regularize the solution by performing a global optical inversion (all altitudes together) strongly constrained by a smooth (although accurate enough) vertical dependence of $r_{m}(z)$ and $\sigma(z)$ as

$$
\begin{aligned}
& r_{m}(z)=r_{\text {min }}+\left(r_{\text {max }}-r_{\text {min }}\right) \exp \left(-\left(\sum_{i=0}^{6} a_{i} z^{i}\right)^{2}\right) \\
& \sigma(z)=\sigma_{\text {min }}+\left(\sigma_{\text {max }}-\sigma_{\text {min }}\right) \exp \left(-\left(\sum_{i=0}^{6} b_{i} z^{i}\right)^{2}\right)
\end{aligned}
$$

where $r_{m}(z)$ and $\ln (\sigma(z))$ are bounded by $\{0.01,1\}$ and $\{0.01,1.5\} \mu \mathrm{m}$ respectively. The inversion consisted in determining the optimal 14 parameters $\left(a_{i}, b_{i}, i=0 . .6\right)$ by using a Levenberg-Marquard scheme. From a total of about 4500 successful inversions, we present in Fig. 1 the solution vertical profiles, averaged over the 9 months of the mission, that were described and validated in Fussen et al. (2001b).

\section{Latitudinal dependence of stratospheric aerosols}

In Fig. 2, we present the mean aerosol number density in a latitude-altitude contour plot. Besides the well-known presence of an aerosol tropical reservoir at about $22 \mathrm{~km}$ (see e.g. Trepte et al., 1994), evidence of a tongue of aerosols can been seen in the southern hemisphere and has been already noticed in the literature (Weisenstein et al., 1997); this seems to be a permanent transport pattern because it is also clearly visible in the large climatology (1984-1994) presented by Thomason et al. (1997).

In order to estimate the effect of advection, we have imported UKMO (United Kingdom Meteorological Office) analyzed meridional and vertical wind velocities during the 


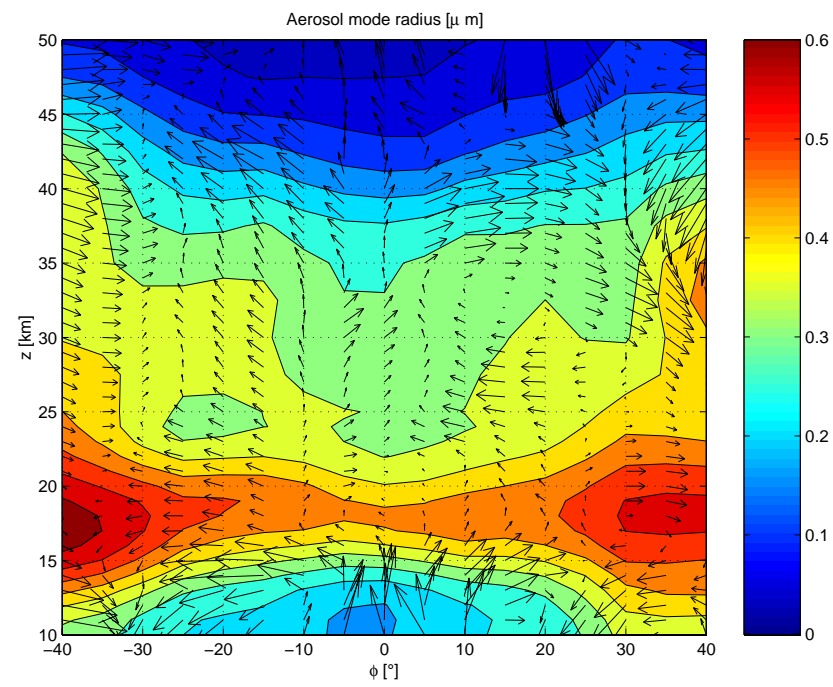

Fig. 3. Same as Fig. 2 but for mode radius $r_{m}$.

mission period. The resulting fields are superposed on Fig. 2 . It is worth noticing that typical orders of magnitude for meridional and vertical velocities are $500 \mathrm{~km} /$ month (mostly poleward) and $1 \mathrm{~km} /$ month (mostly upward), respectively. Sedimentation velocity, which depends on mean size and altitude, equals roughly $0.5,1.5$ and $4.5 \mathrm{~km} /$ month at altitudes of 20,30 and $40 \mathrm{~km}$, respectively. It appears that the mean southward transport can be explained by the dissymmetry in meridional wind velocities in both hemispheres. While a clear upwelling situation prevails between $10^{\circ} \mathrm{S}$ and $10^{\circ} \mathrm{N}$ up to the tropopause, two regions of slightly depleted aerosol levels are visible in the tropics below the tropopause, reflecting the Brewer-Dobson circulation. Similar patterns, including the more intense poleward circulation in the southern hemisphere, have been described in the excellent paper of Wang et al. (1998).

In the $30-50 \mathrm{~km}$ range, there seems to be more particles in the northern hemisphere as a consequence of a large stratospheric circulation cell (referred to as SCC below) whose equatorial upwelling branch connects with a downwelling branch located between $20^{\circ} \mathrm{N}$ and $30^{\circ} \mathrm{N}$.

In Fig. 3, we present the isopleths obtained for the aerosol mode radius together with the velocity fields. The symmetry of the figure is striking, with a general poleward increase of particle size. A very interesting feature is the presence of two symmetrical regions of large particles $\left(r_{m} \simeq 0.6 \mu \mathrm{m}\right)$ located at about $17 \mathrm{~km}$ in the extratropics. The retrieved aerosol mode radius is quite large but fully consistent with published values during the ORA measurement period (effective radii ranging from $0.3 \mu \mathrm{m}$ to $0.8 \mu \mathrm{m}$ were reported by Russell et al., 1996). These regions are also characterized by a weak mean meridional circulation or even a circulation cell in the northern hemisphere. This suggests that regions of low transport can be associated with large particle sizes and a natural explanation for this relationship could be the increased effectiveness of coagulation in stagnation regions

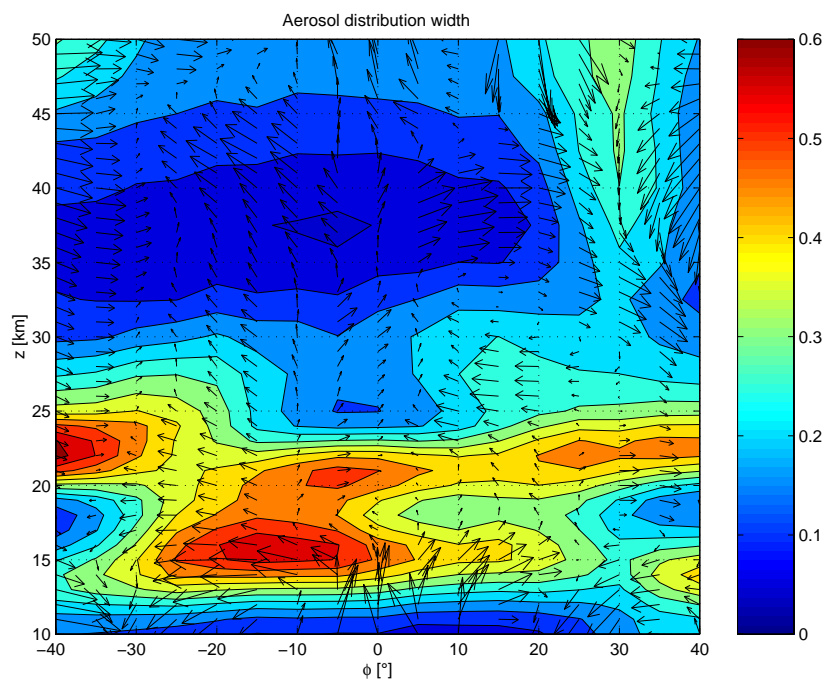

Fig. 4. Same as Fig. 2 but for $\ln (\sigma)$.

where aerosol particles get more time to collide. This would also be the reason for smaller particles in the equatorial upwelling and diverging column. At $30^{\circ}-40^{\circ} \mathrm{N}$ and $30-35 \mathrm{~km}$, one can suspect the presence of another spot of larger particles that could be fed by the above-mentioned large circulation cell (SCC).

In Fig. 4, at an altitude of $15 \mathrm{~km}$ and in the southern tropics, we can see a large increase of the aerosol size distribution width $(\ln (\sigma))$ clearly associated with important poleward meridional transport. Also, the downwelling branch of the SCC is clearly visible. Finally, the stagnation zones are regions of low distribution width and this is coherent with a coagulation mechanism where the distribution width of particles naturally shrinks with time.

\section{Time evolution of the volcanic stratospheric aerosols}

The temporal evolution of volcanic aerosols in the stratosphere remains an open and important question (see e.g. Rosen et al., 1994; Russell et al., 1996). The published relaxation times are of the order about 10 months, which roughly matches the ORA mission period. In particular, the question arises of the reality of a stratospheric aerosol background which is always obscured by successive volcanic eruptions (see Fig. 4 in Osborn et al., 1995). In Fig. 5, we present the results of the latitudinally averaged time-altitude contour plots for $N(z, t)$ and $r_{m}(z, t)$, restricted to the upper troposphere - lower stratosphere domain. Although the aerosol optical thickness was decreasing during the mission period, the net relaxation results from two opposite effects: the number density decreases while the mean size is still increasing (this was suggested with caution by Russell et al., 1996). Note that size increase may induce faster removal as sedimentation velocity (see Fussen et al., 2001b, for details of computation) is proportional to the squared particle radius. Both opposite effects suggest once again that coagulation is 

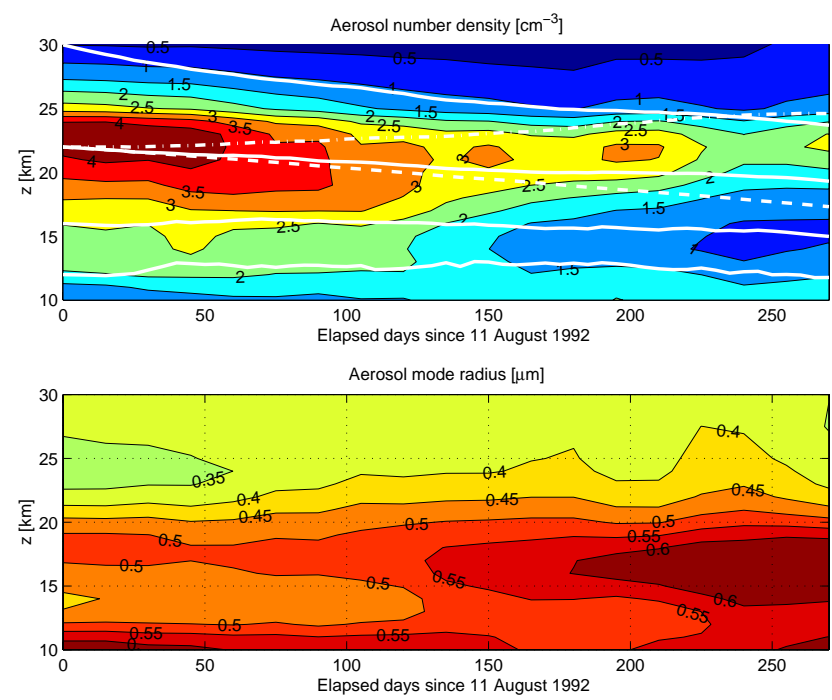

Fig. 5. Top: latitude averaged temporal evolution of $N(t)$. Full lines refer to vertical trajectories starting at $z=12,16,22$ and $30 \mathrm{~km}$, respectively, including transport and sedimentation. The dashed line is the $z=22 \mathrm{~km}$ with sedimentation only while the dotdashed line takes only transport into account. Bottom: temporal evolution of mode radius $r_{m}$.

the main mechanism responsible for changes in the particle size distribution.

Furthermore, there exists a region with a strongly reduced aerosol number density (after 150 mission elapsed days) located at about $15 \mathrm{~km}$ which can be mapped onto the mode radius maximum for the same period. In order to test our interpretation quantitatively, we have integrated the mean vertical velocity starting from altitudes $z=12,16,22$ and $30 \mathrm{~km}$ (see upper plot in Fig. 5). Higher altitude aerosols fall faster because of the mean free path increase (and its influence on the sedimentation velocity) and the trajectory is almost parallel to retrieved number density isopleths. In upper troposphere, weaker sedimentation seems to be counterbalanced by upwelling. For the trajectory starting at the aerosol maximum $(z=22 \mathrm{~km})$, we have integrated the velocity field with transport only $(\mathrm{T})$, sedimentation only $(\mathrm{S})$ and transport + sedimentation $(\mathrm{T}+\mathrm{S})$. It is possible that the inaccurate knowledge of the wind vertical velocity (data users are warned by UKMO) may explain the differences between the final integrated altitude (about $19 \mathrm{~km}$ ), the number density depleted region (around $16 \mathrm{~km}$ ) and the largest radius spot (around $17 \mathrm{~km})$.

We have also developed a simple model to evaluate the degree of anticorrelative evolution between number density and mode radius. Instead of considering the full integrodifferential equation governing the coagulation of a particle population (see e.g. Koziol and Pudykiewicz, 1998), we approximate it by the well-known Smoluchowski equation for the brownian coagulation of an initially monodispersed aerosol (see full mathematical development in Seinfeld and

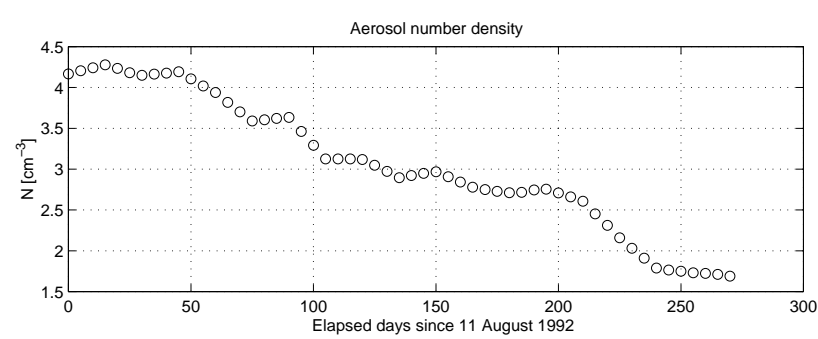

Aerosol mode radius

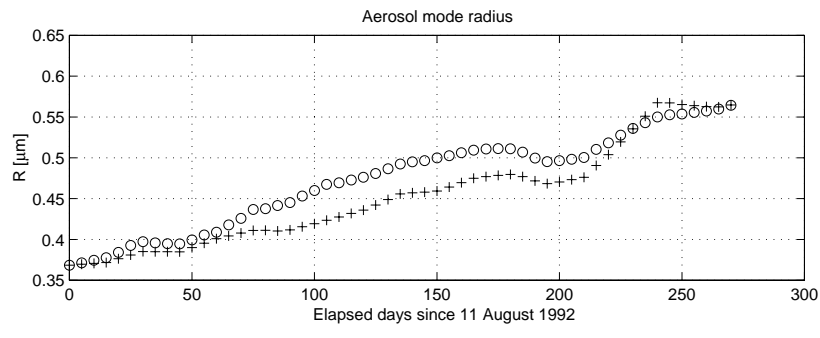

Fig. 6. Top: Retrieved aerosol number density evolution along the $z=22 \mathrm{~km}$ trajectory. Bottom: retrieved(circles) and computed(crosses) mode radius evolution for the same trajectory.

Pandis, 1998). Briefly, one has

$\frac{d N}{d t}=-\frac{K}{2} N^{2}$

where $K$ is the coagulation rate coefficient. This nonlinear equation is easily solved as

$N(t)=\frac{N_{0}}{1+\frac{t}{\tau_{c}}}$

where a characteristic time is defined by $\tau_{c}=\frac{2}{K N_{0}}$ and $N_{0}$ equals the total number density at $t=0$. If we consider $P$ aerosol volume classes with respective volumes $v_{i}=i v, i=$ $1 . . P$, the population $N_{i}$ of class $i$ can be recursively obtained as

$N_{i}(t)=\frac{\left(\frac{t}{\tau_{c}}\right)^{i-1} N_{0}}{\left(1+\frac{t}{\tau_{c}}\right)^{i+1}}, i=1 . . P$

On the other hand, the total aerosol volume will be conserved during the coagulation process and, for a lognormal distribution, one can estimate the mean radius increase as

$\bar{r} \simeq r_{0}\left(\frac{N_{0}}{N}\right)^{\frac{1}{3}} \exp \left(\frac{3}{2}\left(\ln ^{2}\left(\sigma_{0}\right)-\ln ^{2}(\sigma)\right)\right.$

In Fig. 6, we present the results of applying the last formula to the retrieved evolution of $N(t)$ and $\sigma(t)$ along the trajectory starting at $22 \mathrm{~km}$ at the beginning of the ORA mission (11 August 1992). In the lower part of the figure, we compare retrieved and computed temporal evolution of aerosol radius. We conclude that the reasonable agreement is coherent with the coagulation hypothesis, i.e. that the mean aerosol size increase is well correlated with an associated total number density decrease. 


\section{Conclusions}

The role of stratospheric aerosols as a tracer for atmospheric circulation has been recognized by several authors (see e.g. Grant et al., 1996). However, in the latitude range of the ORA experiment $\left(40^{\circ} \mathrm{S}-40^{\circ} \mathrm{N}\right)$ and during a post-volcanic period, our results seem to indicate that their spatio-temporal evolution is understandable but complex. The main factor is certainly the opposite interaction of the general circulation and of the sedimentation. In particular, it should be emphasized that the long term evolution of the aerosol layer must be described with the best available wind velocity fields (and not only by using empirical eddy diffusion coefficients as often done in the literature) since clear signatures of meridional and vertical advections are detectable.

In the upper troposphere-lower stratosphere region, coagulation plays an important role in stagnation regions and probably has a strong influence on the aerosol removal by sedimentation.

Aerosols are usually considered to be almost non-existent above $35 \mathrm{~km}$, based on thermodynamical considerations (see Steele and Hamill, 1981). However, there may be evidence that aerosols coming from the Junge layer can be transported up to altitudes of $50 \mathrm{~km}$, where they are difficult to detect due to their low optical thickness. This could explain the slow decrease of aerosol mode radius with altitude and high altitude circulation patterns detected in the retrieved parameters of the aerosol size distribution. In future work, we plan to investigate data sets of different experiments to test this hypothesis.

Acknowledgements. We thank the United Kingdom Meteorological Office which provided us with the assimilated wind velocities. This study was supported by the Service des Affaires Scientifiques, Techniques et Culturelles of the Belgian government under grant "Measurement, understanding and climatology of stratospheric aerosols (MO/35/004)"

Topical Editor D. Murtagh thanks two referees for their help in evaluating this paper.

\section{References}

Arijs, E., Nevejans, D., Fussen, D., Frederick, P., Ransbeek, E. V., Taylor, F. W., Calcutt, S. B., Werrett, S. T., Heppelwhite, C. L., Pritchard, T. M., Burchell, I., and Rodgers, C. D., The ORA Occultation Radiometer on EURECA, Adv. Space Res., 16, 833836, 1995

Choi, W., Grant, W. B., Park, J. H., Lee, K. M., Lee, H., and III, J. M. R., Role of the quasi-biennal oscillation in the transport of aerosols from the tropical stratospheric reservoir to midlatitudes, J. Geophys. Res., 103, 6033-6042, 1998.

Echle, G., von Clarmann, T., and Oelhaf, H., Optical and microphysical parameters of the Mt. Pinatubo aerosol as determined from MIPAS-B mid-IR limb emission spectra, J. Geophys. Res., 103, 19 193-19211, 1998.

Fussen, D., Arijs, E., Nevejans, D., and Leclere, F., Tomography of the Earth's Atmosphere by the Space-Borne ORA Radiometer: Spatial Inversion Algorithm., J. Geophys. Res., 102, 4357-4365, 1997.
Fussen, D., Arijs, E., Nevejans, D., Hellemont, F. V., Brogniez, C. and Lenoble, J., Validation of the ORA spatial inversion algorithm with respect to the stratospheric aerosol and gas experiment II data, Applied Optics, 37, 3121-3127, 1998.

Fussen, D., Vanhellemont, F., and Bingen, C., Remote sensing of the Earth's atmosphere by the spaceborne occultation radiometer ORA: Final inversion algorithm, Applied Optics, 40, 941-948, 2001a.

Fussen, D., Vanhellemont, F., and Bingen, C., Evolution of stratospheric aerosols in the post-Pinatubo period measured by the occultation radiometer experiment ora, accepted for publication in Atmospheric Environment, 2001b.

Grant, W. B., Browell, E. V., Long, C. S., Stowe, L. L., Grainger, R. G., and Lambert, A., Use of volcanic aerosols to study the tropical stratospheric reservoir, J. Geophys. Res., 101, 39733988, 1996.

Hitchman, M. H., McKay, M., and Trepte, C. R., A climatology of stratospheric aerosol, J. Geophys. Res., 99, 20 689-20 700, 1994.

Junge, C. E., Chagnon, C. W., and Manson, J. E., Stratospheric aerosols, Journal of Meteorology, 18, 80-108, 1961.

Koziol, A. S. and Pudykiewicz, J., High-resolution modelling of size-resolved stratospheric aerosols, J. Atm. Sciences, 55, 31273147, 1998.

Labitzke, K. and McCormick, M. P., Stratospheric temperature increases due to Pinatubo aerosols, Geophys. Res. Lett., 19, $207-$ 210, 1992.

McCormick, M. P. and Veiga, R. E., SAGE II measurements of early Pinatubo aerosols, Geophys. Res. Lett., 19, 155-158, 1992.

Osborn, M. T., DeCoursey, R. J., Trepte, C. R., Winker, D. M., and Woods, D. C., Evolution of the Pinatubo volcanic aerosol over Hampton, Virginia, Geophys. Res. Lett., 22, 1101-1104, 1995.

Rogers, H. L., Norton, W. A., Lambert, A., and Grainger, R. G., Isentropic, diabatic and sedimentary transport of Mount Pinatubo aerosol, J. Geophys. Res., 104, 4051-4063, 1999.

Rosen, J. M., Kjome, N., McKenzie, R. L., and Liley, J. B., Decay of Mount Pinatubo aerosol at mid-latitudes in northern and southern hemispheres, J. Geophys. Res., 99, 25 733-25 739, 1994.

Russell, P. B., Livingston, J. M., Pueschel, R. F., Hughes, J. J., Pollack, J. B., Brooks, S. L., Hamill, P., Thomason, L. W., Stowe, L. L., Deshler, T., Dutton, E. G., and Bergstrom, R. W., Global to Microscale Evolution of the Pinatubo Volcanic Aerosol, Derived from Diverse Measurements and Analyses, J. Geophys. Res., 101, 18 745-18 763, 1996.

Seinfeld, J. H. and Pandis, S. N., Atmospheric Chemistry and Physics, John Wiley \& Sons, New York, 1998.

Solomon, S. R., Portmann, R. W., Garcia, R. R., Thomason, L. W., Poole, L. R., and McCormick, M. P., Role of aerosol variations in anthropogenic ozone depletion at northern midlatitudes, J. Geophys. Res., 101, 6713-6728, 1996.

Steele, H. M. and Hamill, P., Effects of temperature and humidity on the growth and optical properties of sulfuric acid-water droplets in the stratosphere, Journal of Aerosol Science, 12, 517$528,1981$.

Thomason, L. W., Poole, L. R., and Deshler, T., A global climatology of stratospheric aerosol surface area density deduced from stratospheric aerosol and gas experiment ii measurements: 19841994, J. Geophys. Res., 102, 8967-8976, 1997.

Trepte, C. R., Thomason, L. W., and Kent, G. S., Banded structures in stratospheric aerosol distributions, Geophys. Res. Lett., 21, 2397-2400, 1994.

Turco, R. P., Whitten, R. C., and Toon, O. B., Stratospheric aerosols: 
Observation and theory, Reviews of Geophys. and Space Phys., 20, 233-279, 1982.

Wang, P. H., Rind, D., Trepte, C. R., Kent, G. S., Yue, G. K., and Skeens, K. M., An empirical model study of the tropospheric meridional circulation based on SAGE II observations, J. Geophys. Res., 103, 13 801-13818, 1998.
Weisenstein, D. K., Yue, G. K., Sze, M. K. W. K. N. D., Rodriguez, J. M., and Scott, C. J., A two-dimensional model of sulfur species and aerosols, J. Geophys. Res., 102, 13 019-13 035, 1997.

Zhao, J., Turco, R. P., and Toon, O. B., A model simulation of Pinatubo volcanic aerosols in the stratosphere, J. Geophys. Res., 100, 7315-7328, 1995. 